\title{
Inflammatory Myofibroblastic Tumor of the Bronchus Mimicking Asthma
}

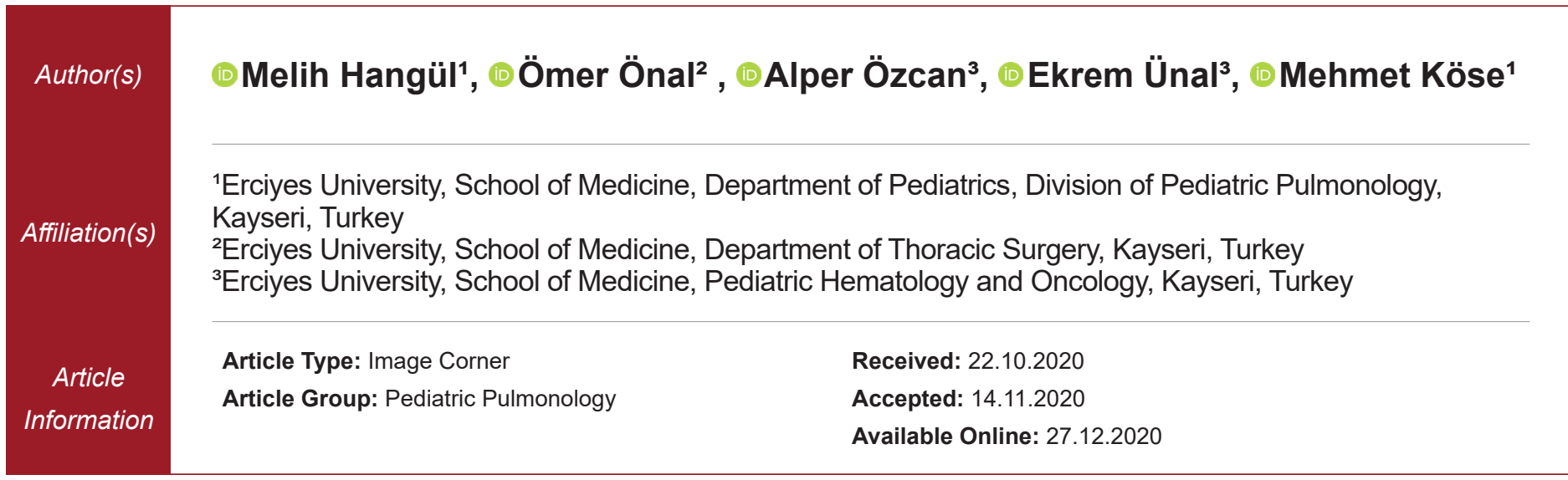

Cite this article as: Hangül M, Önal Ö, Özcan A, Ünal E, Köse M. Inflammatory Myofibroblastic Tumor of the Bronchus Mimicking Asthma. J Pediatr Acad 2020; 1: 103-104.

An 8-year-old girl was referred to the pediatric chest disease department for pneumonia that did not respond to treatment. It was learned that the patient was diagnosed with nonallergic asthma at the age of 6 because of recurrent wheezing episodes and was on inhaled fluticasone and montelukast for 2 years. It was learned that the patient admitted to another hospital with complaints of cough, fever and respiratory distress 15 days before his last admission. The patient, who was started on vancomycin and meropenem treatment, was sent after the radiological findings and tachypnea continued. The patient had tachypnea on respiratory system examination at the time of admission and respiratory sounds were not heard on the left side. Chest X-ray showed total atelectasis in the left lung, mediastinal shift and compensatoryhyperaeration in the right lung (Figure 1). Atelectasis in the lower lobe of the left lung and filling defect in the left main bronchus was observed in the chest radiography taken 1 year ago (Figure 2). An intrabronchial mass lesion obliterating the left main bronchus was observed in the thoracic computed tomography (Figure 3). In fiberoptic bronchoscopy, a polypoid mass lesion, $2 \mathrm{~cm}$ below the carina, completely obliterating the left main bronchus (Figure 4 ), was observed and biopsy was taken. The final diagnosis was Inflammatory myofibroblastic tumor (IMT). According to the pathology report ALK inhibitor crizotinib was given to the patient. The patient is being followed in remission. IMT Primary lung tumors are very rare in childhood (1). IMT is the most common benign tumor of the lung in children. Since the clinical picture of lung tumors is nonspecific and they are rare, it is not considered in the differential diagnosis of lung diseases in children. In the treatment, total excision is performed and the prognosis is excellent (2). Asthma is the most common chronic pediatric disease in the worldwide and most common cause of wheezing in children. Patients with asthma who do not respond to appropriate treatment and have atelectasis on chest X-ray should be investigated in detail for other causes of wheezing (3).

Author Contributions: MK conceived the study. $\mathrm{MH}$, ÖO, $A O ̈, E U ̈$, and $M K$ were involved in patient care, including the process of procedure and routine clinical follow-up. $\mathrm{MH}$, $A O ̈$ and MK performed the literature review and wrote the manuscript. ÖO, EÜ, and MK also made helpful suggestions to improve the manuscript.

Conflict of Interest: The authors have no conflict of interest to declare.

Correspondence: Mehmet Köse, Erciyes University, School of Medicine, Department of Pediatrics,

Division of Pediatric Pulmonology, Kayseri, Turkey

E-mail: mhmtkose@yahoo.com 
Financial Disclosure: The authors declared that this study has received no financial support.

Informed Consent: Written informed consent was obtained from patients who participated in this study.

Peer-review: Externally peer-reviewed.
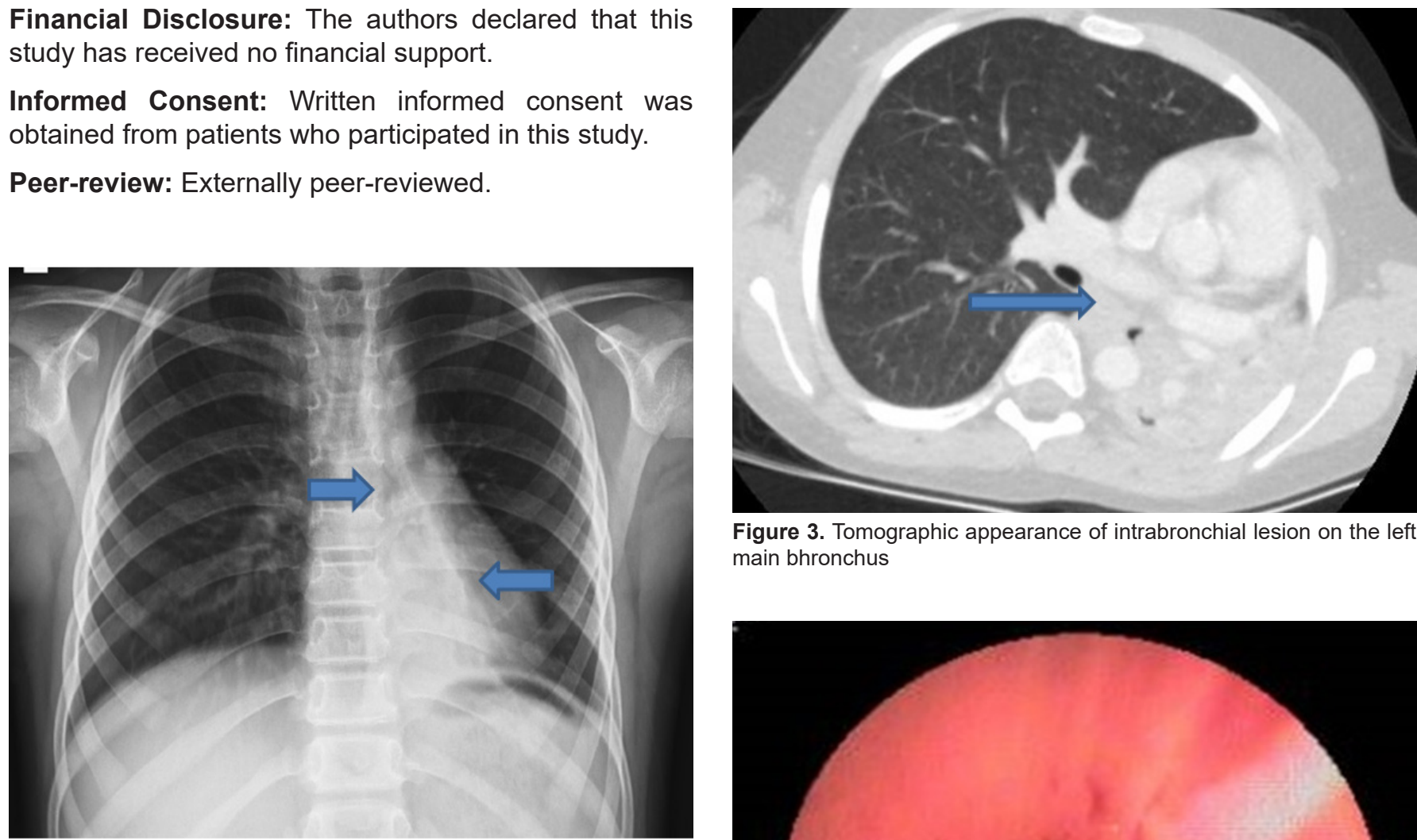

Figure 3. Tomographic appearance of intrabronchial lesion on the left main bhronchus

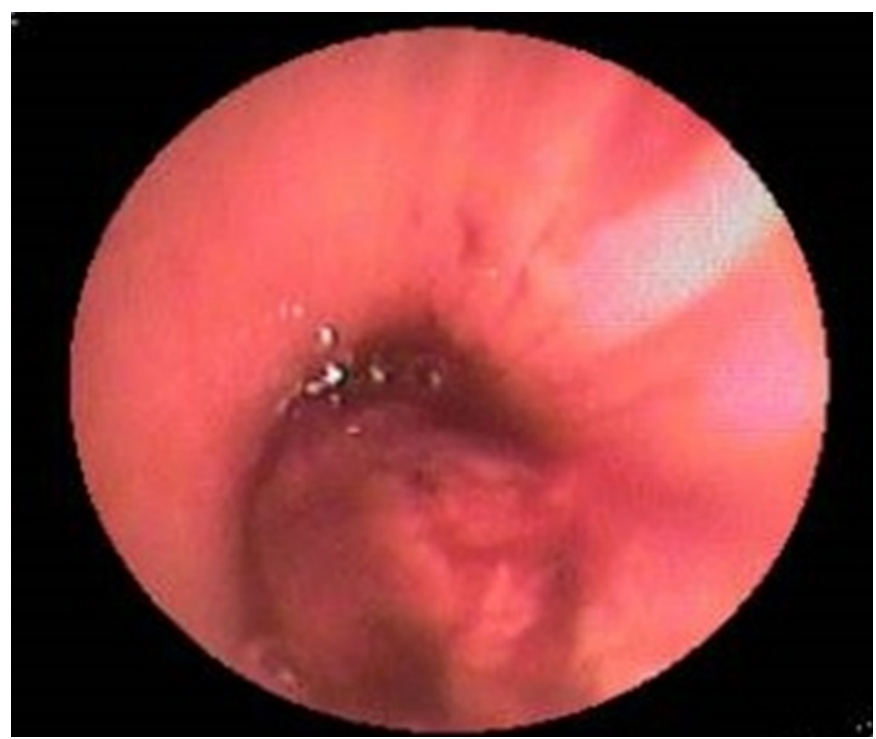

Figure 4. Fiberoptic bronchoscopic image of polipoid mass in the left main bronchus

\section{References}

1. Balkanlı S, Özturk MA, Köse M, et al. A report of adenocarcinoma in situ and congenital pulmonary airway malformation in a threeday-old infant with a review of the literature. Turk J Pediatr. 2014;56:299-302. [CrossRef]

2. Surabhi VR, Chua S, Patel RP, Takahashi N, Lalwani N, Prasad SR. Inflammatory Myofibroblastic Tumors: Current Update. Radiol Clin North Am. 2016;54:553-563. [CrossRef]

3. Kercsmar CM, Mcdowel KM. Wheezing in older children: asthma. In: Wilmonth RW, Deterding R, Li A, Ratjen F, Sly P, Zar HJ, Bush A. (eds). Kendig's Disorders of the Respiratory Tract in Children, 9th ed. Philadelphia,Elsewier, 2019, 686-721.

Figure 2. ChestX-ray at the admission showing left lung atelectasis mediastinal shift and hyperaeration of right lung 